\title{
Historiografía sobre el territorio lebaniense en la Edad Media (1831-2012)*
}

\author{
Modern Historiography Concerning the Medieval Territory \\ of Liébana (1831-2012) \\ Elisa Álvarez LLOPIS **
}

\begin{abstract}
RESUMEN ABSTRACT
El objetivo de este breve estudio es sintetizar en unas páginas las características de la producción histórica que, sobre el territorio lebaniense en la Edad Media se ha escrito desde 1831 hasta 2012.

The aim of this brief study is to summarize in a few pages the main features of the historical production concerning the territory of Liébana from 1831 to 2012.

PALABRAS CLAVE

KEY WORDS

Liébana, territorio lebaniense, historiografía.

Liébana, the Territory of Liébana, Historiography.
\end{abstract}

\section{LA LIÉBANA COMO OBJETO DE INVESTIGACIÓN}

La evolución de la historiografía, sea esta nacional, regional o local, se apoya, sin duda alguna, sobre el trabajo acumulado a lo largo de generaciones. Trabajo de personas que han dedicado parte de su tiempo a intentar explicar los procesos que desde épocas antiguas han llevado a la actualidad. La historiografía es, por consiguiente un esfuerzo colectivo y acumulativo. Por tanto, ningún trabajo individual puede desconocer los estudios ajenos, sean estos archivísticos, arqueológicos o de carácter general, realizados por generaciones anteriores como expresión de la cultura regional realizada. A través de ellos podemos conocer los fundamentos históricos sobre los que se ha ido construyendo la historia de Liébana.

Una aproximación al territorio lebaniense o a La Liébana como objeto de investigación nos ha llevado a realizar una revisión historiográfica de los libros y

* Fecha de recepción del artículo: 2013-06-12. Fecha de aceptación del artículo: 2013-11-18.

** UNED - C. A. Cantabria. C.e.: ealvarez@santander.uned.es 
artículos editados entre los años 1831 a 2012, sea a título particular o editados en torno a la conmemoración de los actos del Jubileo de Santo Toribio, de las obras de Beato de Liébana; y de una historia más especializada, más rigurosa en sus planteamientos teóricos y metodológicos. La suma de todo ello da como resultado en torno a los 500 títulos. Queremos aclarar que en esta revisión hemos obviado artículos de prensa diaria, al igual que todos aquellos títulos editados o virtuales y páginas web de carácter claramente económico-turístico y muchas veces criticables por incluir noticias históricas distorsionadas o relacionadas con una tendencia política determinada. Aún así, hemos recogido algunos que creemos que a pesar de tener una escasa o ínfima aportación científica, si tienen significado como expresión historiográfica del pasado.

Este número de publicaciones tiene dos etapas claramente diferenciadas. Una, que se extiende entre los años 1831-1970: un período este casi lineal en los temas (arte y viajes) y en el número de títulos; y otra, que se desarrolla a partir de los años 1970 a la actualidad. En esta última etapa, se multiplican los temas y los títulos, pudiendo atribuirse su causa a la creación de la Facultad de Filosofía y Letras de Santander y a la constitución de la Comunidad Autónoma de Cantabria.

La búsqueda de una redefinición de espacios culturales y políticos por parte de las diferentes Comunidades Autónomas ha originado la aparición de una historiografía regional reivindicativa por parte de las entidades oficiales regionales, deseosas de impulsar el desarrollo turístico y económico de sus comunidades y de crear una conciencia colectiva en una sociedad en la que todavía hoy persisten lealtades de valle o de comarca o de vínculos hacia Castilla. Por ello, al intentar construir una historia colectiva y unitaria para toda la comunidad se han apoyado temas que, unas veces se han magnificado con un tono profesional, mientras que otras rozan la «frivolidad cultural».

En los gráficos que insertamos a continuación se puede observar esta proliferación de temas y de trabajos más representativos del desarrollo historiográfico que tienen como protagonista total o parcialmente al territorio lebaniense. 


\section{Historiografía}
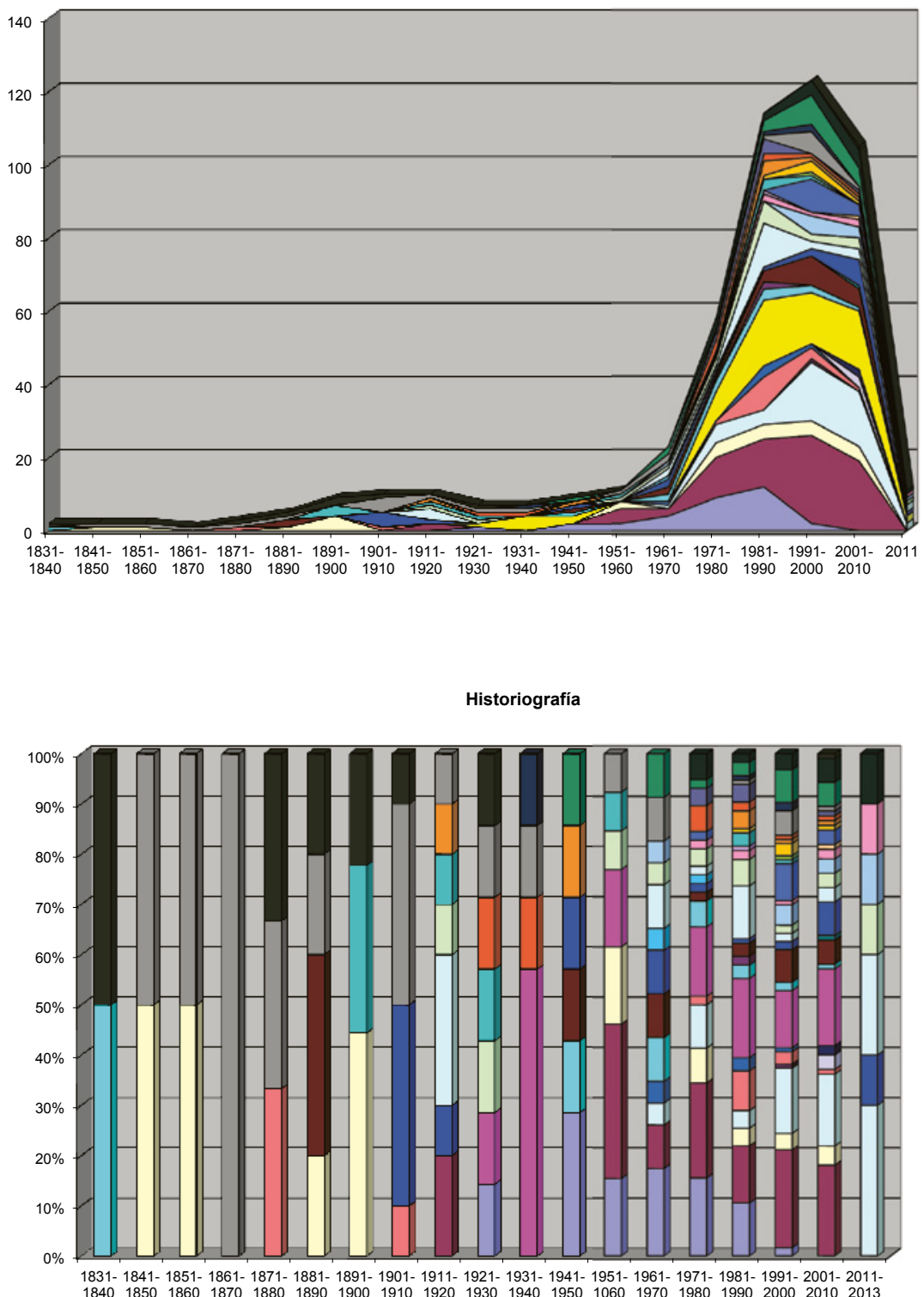


\section{LÍNEAS DE INVESTIGACIÓN}

Una aproximación a los 500 títulos seleccionados en relación con la historiografía lebaniega nos permite agrupar los trabajos según sus líneas de investigación dominantes y valorar sus propuestas e interpretaciones.

La atención a las fuentes documentales o escritas destaca como uno de los temas prioritarios desde fechas tempranas con tres ámbitos de atención. El primero de ellos el de la documentación monástica. Los monasterios de Santo Toribio y Santa María de Piasca son los principales protagonistas de la atención; especialmente la documentación del primero desde las tempranas publicaciones de Eduardo de Jusué, E y Luis Sánchez Belda, de los años 1904, 1905 y 1906 y 1948, respectivamente sobre su Cartulario, hasta la más reciente de Alvarez Llopis, E, Blanco Campos, E, y García de Cortázar, J. A ${ }^{1}$, que complementa la de los dos autores anteriores. Es también notable la edición de los Apeos de Santo Toribio llevada a cabo por Vasallo, R.,

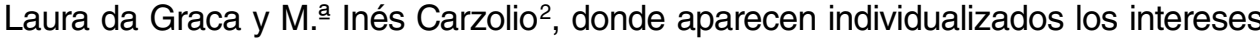
del monasterio en los distintos valles lebaniegos. Tanto la edición de la Colección diplomática como del apeo se realizó dentro del Proyecto Documentación Histórica de Cantabria (DOHISCAN) de la Fundación Marcelino Botín, dirigido por el catedrático de Historia Medieval de la Universidad de Cantabria José Ángel García de Cortázar.

Además de esta documentación, se pueden localizar otros registros documentales de los monasterios de Santo Toribio y de Piasca insertos en las ediciones de las fuentes documentales de los Archivos del Monasterio de San Salvador de Oña, del Monasterio de Sahagún o en el de Santiago de León, así como en otras áreas del Archivo Histórico Nacional y en pequeños artículos, como los relativos a beneficios, abadalogio o a un formulario del Monasterio de los siglos XVI y XVIII.

Menor atención ha sido la prestada al monasterio de Santa María de Piasca. El manuscrito original de su cartulario del siglo XII presenta algunos problemas diplomáticos que le restan fiabilidad. Se encuentra en la Biblioteca Municipal de Santander; y en el se insertan 65 documentos hasta el año 1167. El archivo del monasterio de Sahagún suministró otros 57 documentos, es decir, un total de 186 registros a la trascripción realizada por Julia Montenegro ${ }^{3}$ de los años 857 a 1252. Esta obra fue objeto de bastantes problemas surgidos a la hora de su edición en 1993 con la entidad oficial correspondiente y contiene algunos registros documentales incompletos en su contenido. Sobre los documentos de Santa María de Piasca han trabajado igualmente Maza Solano, $\mathrm{T}^{4}$ y Fray Justo Pérez de Urbel que

1 ÁLVAREZ LLOPIS, E., BLANCO CAMPOS, E., y GARCÍA DE CORTÁZAR, J. A.: Colección Diplomática de Santo Toribio de Liébana (1300-1515), Santander, Fundación Marcelino Botín, 1994.

2 VASALLO, R., LAURA DA GRACA y M. . INÉS CARZOLIO: Apeos de Santo Toribio de 1515 y 1538 Santander, Fundación Marcelino Botín, 2001.

${ }^{3}$ MONTENEGRO VALENTÍN, J.: Colección Diplomática de Santa María de Piasca (857-1252) Santander, Diputación Regional, s. ed. s.f.

${ }^{4}$ MAZA SOLANO, T.: «Santa María de Piasca: (un manuscrito de 1519)» en Boletín de la Biblioteca Menéndez Pelayo, I (1919), pp. 128-141. 
incluía en el índice documental de su Historia del Condado del Condado de Castilla ${ }^{5}$ algunos documentos procedentes de este cenobio en los que se evidencian algunos errores a la hora de su datación.

Recientemente, se han publicado dos obras por parte de J. A González Cote$\mathrm{ra}^{6}$. A su meritoria labor de poner a disposición de la comunidad científica estas fuentes le resta valor su deseo de hacer aparecer una documentación inédita sin llevar a cabo una edición rigurosamente crítica, que se manifiesta especialmente en la segunda obra en detalles archivísticos tales como la falta de localización del manuscrito, de información de su estructura y contenido, de las normas de transcripción empleadas por el autor, la dificultad de su lectura y un índice toponímico mal estructurado.

Otro tipo de fuentes editadas son textos incluidos en breves artículos de carácter social o relativo a la administración local. Hidalgos y grandes propietarios sirven de base para la realización de los breves artículos de Porro o Pontieri, Duart Gaitero, Pérez Bustamante. De carácter administrativo son la recopilación de Ordenanzas de los lugares de Liébana editadas por Baró Pazos y Pérez Bustamante.

Un segundo grupo de fuentes son las integradas por los registros arqueológicos. En Cantabria, la mayor parte de las actuaciones en las últimas décadas se han Ilevado a cabo en lugares ya conocidos: El Pendo, El Castillo, Altamira... Comprensible, quizá, por la necesidad de afinar cronologías, estratigrafías o la incorporación de nuevos recursos de apoyo a la excavación. Lejos de estos objetivos quedaba el territorio lebaniense, donde la información tenía un carácter epigráfico. Las lápidas vadinienses $u$ orgenomescas son las protagonistas de los trabajos de Fidel Fita y otros autores (14). A ellas se pueden agregar las estelas romanas de Luriezo o Villaverde, o los casuales hallazgos de Bárago o Potes. Es a partir de los años 80 del siglo pasado cuando se inicia un punto de inflexión y diversificación en los objetivos: megalitos, hachas, necrópolis, cuevas, etc., surgen en la historiografía local de la mano de Díez Castillo ${ }^{7}$ Teira Mayolini ${ }^{8}$ como resultado de sus respectivos estudios de doctorado. El Paleolítico (El Habario), el Musteriense (El Esquilleu), el Aziliense (La Mina) van sumándose a los conjuntos megalíticos de la Peña Oviedo o de Pico Jano, del collado de Las Llaves y La Mora, que nos van informando sobre la cultura material y la ocupación del espacio lebaniense en época prehistórica.

5 PÉREZ DE URBEL, FR. J.: Historia del Condado del Condado de Castilla, Madrid, C. S. I. C, Escuela de Estudios Medievales, 1945, Apéndice III, pp. 1369-1382.

${ }^{6}$ GONZÁLEZ COTERA J. M. a: Pasajeros a Indias de Liébana y sus valles circundantes 1503-1790, según la documentación del Archivo General de Indias. Ed. digital, 2005 y Apeo del Monasterio de Santa María la Real de Piasca. Años de 1532, Ed. digital 2012.

7 DÍEZ CASTILLO, A.: Inventario arqueológico de la comarca de Liébana: evolución, historia y poblamiento, Santander, Universidad de Cantabria. (Tesis doctoral, s. p.) 1991.

8 TEIRA MAYOLINI, L.: EI megalitismo en Cantabria: aproximación a una realidad arqueológica olvidada, Santander, Universidad de Cantabria, 1994. 
En este panorama arqueológico que se va abriendo se puede incluir un nuevo elemento: los castros de la Edad del Hierro. Objeto de un estudio monográfico: Castros y Castra en Cantabria, fortificaciones desde los origines de la Edad del Hierro a las guerras con Roma. Catálogo, revisión y puesta al día ${ }^{9}$, en edición digital, que recoge en sus páginas un informe sobre el área de Liébana en el que se incluyen como posibles ocho castros o recintos defensivos. La información nos parece demasiado optimista, pues sólo se aportan datos visuales con alguna aportación de elementos hallados en superficie y fuera de contexto. Son localizaciones de gran altura, sin ningún tipo de cronología o datación, en las que ha habido intervenciones de obras públicas, mineras o de los habitantes próximos en ellos. Asimismo, pensamos que la utilización de la microtoponimia para plantear la posible localización de lugares defensivos es bastante aventurada, ya que la toponimia puede suministrar información en relación con algunos aspectos como la fisonomía o la morfología del territorio por ejemplo, pero no se puede hablar de etapas de ocupación. Y es evidente que muchos topónimos pueden vincularse lingüísticamente a un origen prerromano, romano o medieval. Si sumamos, según los datos aportados para Liébana en la citada obra, los posibles lugares defensivos localizados por medio de la microtoponimia, resultaría un número próximo a 47, además de los ocho anteriores; es decir un total de 55, lo que nos parece excesivo teniendo en cuenta la extensión y morfología del valle de Liébana y la demografía de la época.

Desde presupuestos arqueológicos, toponímicos y antropológicos Díez CastiIlo, Císneros y Ramírez Sádaba ${ }^{10}$ han intentado establecer los patrones de asentamiento en Liébana mediante el análisis de los elementos que suponen una evolución interna de la comunidad, y los que se manifiestan a partir de estos elementos en un período que oscila desde la aparición del metal hasta época romana. La escasez de los registros arqueológicos para determinadas épocas ha generado un resultado modesto al tener que extrapolar los datos de un determinado período para una cronología tan amplia como la planteada.

Puestos a seguir con este enunciado de la cultura material parece que la arqueología medieval comienza a moverse en Liébana con las actuaciones en la ermita rupestre de Cambarco, la necrópolis de Maredes o las ecclesiae alto medievales de Osina, Aguas Calidas, San Pelayo, Naranco y San Vicente de Potes. Pero sus resultados han sido más bien escasos y sigue la duda sobre el emplazamiento de las dos primeras. Se ha consolidado la ruina de San Pelayo en Peñarrubia, que formaba parte del antiguo territorio lebaniense. El Proyecto Nansa de la Fundación Marcelino Botín ha evidenciado las labores de conservación de las

9 SERNA GANCEDO, M., MARTÍNEZ VELASCO, A. y FERNÁNDEZ ACEBO, V. (coord.): Castros y Castra en Cantabria: fortificaciones desde los orígenes de la edad del Hierro a las guerras con Roma: catálogo, revisión y puesta al día, pp. 169-170. ed. digital (2010).

${ }^{10}$ CISNEROS, M., DÍAZ CASTILLO, A. y RAMÍREZ, J. L.: «Bases para el estudio del poblamiento romano en Cantabria: la comarca de Liébana» en Saguntum. Papeles del laboratorio de Arqueología de Valencia, 28 (1995), pp. 185-196. 
ruinas de las torres de Verdeja, Piehedrahíta, del Pontón, de una casa fuerte y la localización de elementos góticos en algunas casas del valle. La actuación en la ermita de Cueva Santa ha permitido conocer su adscripción al siglo VII y la intervención realizada en el monasterio de Santa María de Piasca ha permitido levantar su planimetría. Lejana queda la excavación llevada a cabo por García Guinea en el monasterio de Santo Toribio (1964-65) bajo el crucero de la iglesia y junto el presbiterio con objeto de aclarar las vicisitudes arquitectónicas del edificio y su posible antigüedad: sus resultados fueron más bien escasos y se hacen necesarias nuevas actuaciones.

Este desarrollo de la arqueología medieval ha permitido conocer los frutos de la intervención en este ámbito de conocimiento con motivo de la restauración de la Torre del Infantado y del castillo del monte Subiedes por parte de Lino Mantecón y Javier Marcos ${ }^{11}$. La intervención arqueológica, además, ha logrado recuperar un pequeño lote de cerámicas de adscripción altomedieval, así como un conjunto de piezas metálicas. La datación absoluta procedente de los cimientos del castillo ha desechado cualquier vinculación con los orígenes del Reino Asturiano y ha permitido datar su construcción entre fines del siglo X y principios del XI.

Un tercer punto de atención han sido las fuentes lingüísticas, y más concretamente, la Onomástica. La toponimia es una base significativa para el conocimiento histórico y sumamente útil para el medievalista, pero a veces problemática por los diferentes criterios etimológicos dados sobre cada uno de los topónimos y por su falta de precisión cronológica. El análisis toponímico sólo nos permite establecer etapas en la formación de los topónimos, conocer la realidad geográfica que designan, el aspecto del terreno, la vegetación, la fauna, los fenómenos de repoblación, pero en ocasiones la etimología popular y hasta el tabú ha podido influir en el cambio de un topónimo. Con respecto a la Antroponimia, su estudio ha contribuido a la historia de la lengua, al evolucionar los nombres de persona de forma paralela a los acontecimientos históricos.

Los estudios de Ramírez Sádaba, Montenegro Valentín, Álvarez Llopis o Canal Sánchez han contribuido desde los años 1990 ha conocer el origen toponímico de los nombres de lugar, de los hagiónimos y la utilización de la toponimia como medio de análisis de la organización social del espacio. De estos estudios se deduce la presencia y capacidad de adaptación de los pueblos prerromanos que ocuparon Liébana por los abundantes vestigios dejados sobre el terreno. Especialmente, en los cursos de agua. Del análisis antroponímico de las aldeas de Potes, Argüébanes y Turieno se concluye que de los 214 nombres de personas diferentes documentadas entre los siglos IX a XIII, casi el $50 \%$ son de origen germánico y por

11 MANTECÓN, L. y MARCOS, J.: «El castillo de Monte Subiedes (Camaleño, Liébana, Cantabria); control del territorio lebaniego en la Alta Edad Media», en Territorio, sociedad y poder: revista de estudios medievales, 4, (2009), pp. 95-129. 
otro, que entre los veinticinco los nombres más utilizados en la Liébana medieval los de Pedro y María eran los más frecuentes.

El análisis aplicado a la hagionimia ha probado que las advocaciones de los lugares de culto lebaniegos, son las propias de un cristianismo primitivo, ya que predominan los nombres de mártires de tradición hispánica y los de los apóstoles.

Los textos escritos, los testimonios materiales o los nombres de lugar y persona son fuentes de conocimiento que buscan un apoyo decidido por parte de las arqueológicas, aunque muchas veces sean las primeras las que apoyen a las segundas, como se puede deducir de los informes arqueológicos que hemos consultado. Informes estos que todavía siguen siendo una mera descripción de los hallazgos o unas tesis posibilistas más que una información sobre las características de un grupo humano sobre el terreno, de su explotación por el mismo, de sus hábitos culturales, y, como no, de su estructura social. Pero todo esto no es más que un deseo, la realidad es que los trabajos realizados en Liébana son escasos y aislados, procedentes de acciones fortuitas como resultados de una arqueología de urgencia no rigurosa ni sistemática, por lo que los resultados son insuficientes y provisionales. No se han promovido campañas regulares, planificadas para analizar un proceso sino que estas son casuales. Y por ello, es necesaria la planificación de las actuaciones, así como el apoyo económico de las correspondientes entidades oficiales.

La segunda línea de trabajo corresponde a la figura de Beato de Liébana. Desde que en el siglo XVIII el padre Florez publicara la primera edición crítica del libro Sancti Beati, Presbyteri Hispani Libanensis, In Apocalypsim o Exposición del Apocalipsis de Beato de Liébana, muchos han sido los que han intentado buscar relaciones entre los códices conservados para profundizar el estudio del autor y su época. Cincuenta y dos son los títulos de variado contenido que hemos contabilizado desde 1960. Exposiciones, facsímiles, estudios sobre la lengua, la cultura, sus ilustraciones, las trompetas y las cítaras, el mapamundi, etc, son algunos de los temas que se repiten en libros artículos y congresos. Incluso Umberto Eco hace su aportación al estudio del milenio y de las miniaturas ${ }^{12}$. Muchos son los estudios sobre el Apocalipsis pocos los que se refieren a aspectos de su vida religiosa y política en el Reino Astur, como Isla Frez ${ }^{13}$ o González Echegaray ${ }^{14}$; y la gran mayoría de los estudios son realizados con motivo de los distintos jubileos celebrados hasta el momento, que algunos autores han aprovechado para repetir y editar sin nuevas aportaciones el contenido de su obra con ocasión de los jubileos del 2000 y 2006.

12 ECO, Umberto: «Beato de Liébana, el Apocalipsis y el Milenio» en Los cuadernos del Norte. Revista cultural de la Caja de Ahorros de Asturias, año n.ำ 3, n.ำ 14, (1982), pp. 2-20.

13 ISLA FREZ, A.: El adopcionismo y las evoluciones religiosas y políticas en el Reino Astur, en Hispania, vol. 58, n.ำ200, (1998), pp. 971-993.

14 GONZÁLEZ ECHEGARAY, J.: «Beato de Liébana y los terrores del año 800 « en Milenarismos y Milenaristas en la Europa Medieval, IX Semana de Estudios Medievales, Nájera, 1998, coord. J. E. de L Iglesia duarte, pp. 187-100. 
Una nueva iniciativa, la música popular, inédita hasta ahora, parece abrirse en Liébana desde 1977 con la publicación de Matilde Camus del Cancionero de Liébana ${ }^{15}$. La reproducción de la obra de Francisco de Velasco de 1604, los cánticos religiosos populares y las grabaciones sonoras realizadas por Grazia Tuzi son parte de las ocho obras editadas en relación con el cancionero popular de Liébana que se han sucedido desde entonces en esta labor de recuperación.

Llegamos a una vía de investigación que a lo largo de estos años parece que ha gozado, en teoría, de gran interés, la Historia de Liébana. Pero la realidad tiene distinto signo. Vayamos por partes.

La aproximación a la historia de Cantabria y de Liébana en particular ha sido desigual. En ella que han primado más los trabajos de tipo artículo descriptivo que las obras de investigación o de síntesis, predispuestas a que cada investigador se perfile como un especialista de su tema

Existen obras de tema histórico con una visión integradora de los distintos espacios regionales, como La Edad Media en Cantabria (1985), Historia de Cantabria (2007). Otros estudios reflejan una realidad histórica administrativa, como el Libro Becerro de las Behetrías; análisis de ámbitos territoriales que son el resultado de una evolución político-administrativa, como La formación de la sociedad feudal en Cantabria de Díez Herrera ${ }^{16}$; sobre el origen de la cristianización y los aspectos de la organización interna de la iglesia y los monasterios en Cantabria en la Alta Edad Media: organización eclesiástica y relaciones sociales de Loring García ${ }^{17}$; el planeamiento del funcionamiento de la sociedad y los procesos de aculturación entre comienzos del siglo VIII y fines del XI queda plasmado en la obra conjunta de J. A. García de Cortázar y Díez Herrera ${ }^{18}$. En esta última obra se puede observar el verdadero gradiente de situaciones históricas en que cada uno de estos espacios se mueve y las diferentes secuencias en la recepción y aclimatación de pautas culturales. Todas las anteriores son investigaciones que, bajo un epígrafe general ofrecen ejemplos de procesos que tienen lugar en el territorio lebaniense.

La organización social del espacio es otra de las líneas de investigación a cargo de Álvarez Llopis en la que se analiza alguna de las fases del proceso en el ámbito regional, como su tesis sobre la Liébana Medieval siglos IX a XIII. Instalación humana y actividades económicas ${ }^{19}$, un resumen de la misma en «Introduc-

\footnotetext{
15 CAMUS, M.: Cancionero de Liébana, Santander, J. Bedia, 1976.

${ }^{16}$ DíEZ HERRERA, C.: La formación de la sociedad feudal en Cantabria, Santander, Universidad de Cantabria, 1990.

17 LORING GARCÍA, I.: Cantabria en la Alta Edad Media: organización eclesiástica y relaciones sociales. Madrid, Universidad Complutense, 1987.

${ }^{18}$ GARCÍA DE CORTÁZAR, J. A. y DÍEZ HERRERA, C.: La formación de la sociedad hispano-cristiana del Cantábrico al Ebro en los siglos VIII a XI. Planteamiento de una hipótesis y análisis del caso de Liébana, Asturias de Santillana y Trasmiera. Santander. Ed. Estudio, 1982.

19 ÁLVAREZ LLOPIS, E.: La Liébana Medieval siglos IX a XIII. Instalación humana y actividades económicas (Tesis doctoral, s. p.) Universidad de Cantabria, 1994.
} 
ción a la Liébana medieval»20; de las unidades de ordenación del espacio como la aldea, el solar y la casa en «Aldeas y solares en Liébana: Argüébanes, Turieno y Potes» ${ }^{21}$, y en colaboración con Peña Bocos «La Maison paysanne dans le Nordouest de la Péninsule Ibérique au Bas Moyen Age: Une cellule de base de l'organisation sociale de l'espace» ${ }^{22}$. En esta línea, la formación de cada aldea en relación con otras aldeas se deduce por medio de una serie de síntomas, mientras que la formación interna de la aldea dentro de un marco territorial conocido es un proceso más lento y desigual según los diferentes núcleos. Por su parte en «La toponimia de Liébana: nuevas propuestas de organización social del espacio» ${ }^{23} \mathrm{se}$ analiza la ocupación del espacio a través del conjunto de la toponimia, tratando de observar la adecuación de los vocablos a la toponimia y la influencia de los diferentes sustratos lingüísticos que han dejado huella en el territorio.

Sobre las actividades económicas las síntesis elaboradas presenta dos líneas diferentes de actuación: una sobre el territorio, protagonizadas por García Sahagún en un reducido y sistemático trabajo sobre La organización del espacio ${ }^{24}$ y por Álvarez Llopis, que en su tesis aporta un sistemático análisis sobre las actividades económicas de los valles lebaniegos. De fechas posteriores son los trabajos de Campos Cantera y Lanza García ${ }^{25}$ en el que se definen de forma breve y esquemática los elementos del paisaje agrario de una comunidad.

La segunda línea tiene como actor principal al monasterio de Santo Toribio. Gautier-Dalché editaba un estudio sobre su dominio en un extenso artículo en $1965^{26}$, y posteriormente lo harían las historiadoras argentinas M. ${ }^{\text {I Inés Carzolio }}{ }^{27}$ y R. Vasallo en su tesis ${ }^{28}$. En esta última se abordan problemas relacionados con

20 Ídem. «Introducción a la Liébana medieval» en SÁNCHEZ GÓMEZ, M. A. y ESTRADA, M., ed. La Liébana: una aproximación histórica, Torrelavega, 1996, pp. 77-92.

${ }_{21}$ Ídem. «Aldeas y solares en Liébana: Argüébanes, Turieno y Potes» en Del Cantábrico al Duero: trece estudios sobre organización social del espacio en los siglos VIII a XIII, coord. J. A. García de Cortázar, Santander, Universidad de Cantabria, 1999, pp. 189-228.

22 Ídem. ÁlVAREZ LLOPIS, E. y PEÑA BOCOS, E.: «La Maison paysanne dans le Nord-ouest de la Péninsule Ibérique au Bas Moyen Age: Une cellule de base de l'organisation sociale de l'espace» en Maisons paysanne en Europe occidentale. $X V^{\mathrm{e}}-X X \mathrm{I}^{\mathrm{e}}$ siècles, Jean-René Trochet (dir), Presses de l'Université París-Sorbone, 2008, pp. 17-30.

23 ÁLVAREZ LLOPIS, E.: «La toponimia de Liébana: nuevas propuestas de organización social del espacio» en La onomástica en Navarra y su relación con la de Europa. Actas de las primeras Jornadas de Onomástica (Pamplona, 2003), J. L. Ramírez Sádaba (coord). Universidad Pública de Navarra, Pamplona, 2005.

24 GARCÍA SAHAGÚN, J.: La organización del espacio agrario en Liébana durante la Edad Media. Santander, Tantín, 1986.

25 CAMPOS CANTERA, J. y LANZA GARCÍA, R.: Paisaje rural y estructuras agrarias en un concejo lebaniego a mediados del siglo XVIII. Santander, Tantín, 1985.

${ }^{26}$ GAUTIER-DALCHÉ, J.: «Le domaine du monastère de Santo Toribio de Liébana: formation, structure et modes d'explotation» Anuario de Estudios Medievales, 2, (1965), p. 63-117.

27 CARZOLIO, M. ${ }^{\text {a }}$ I.: « Formas de gestión del patrimonio monástico en Santo Toribio de Liébana, siglos XV y XVI» Cuadernos de Historia de España, n.ำ74, (1997), pp. 29-66.

${ }_{28}$ VASALLO, R.: Estructura y dinámica del dominio de Santo Toribio de Liébana (siglos XIII-XVI. Universidad Nacional de La Plata (Argentina), 2009. ed. digital. 
la formación y consolidación del señorío, así como las formas diferenciales de dominación que permitieron la consolidación del dominio.

Una línea mixta es la seguida por Montenegro Valentín al combinar en su trabajo la historia de un dominio y las familias a él vinculadas en su obra sobre Santa María de Piasca ${ }^{29}$. A su meritoria obra le resta valor los problemas a la hora de editar las fuentes que acompañaban a su estudio, ya que éstas no fueron editadas conjuntamente y es imposible contrastar las referencias a las mismas que se hacen en la obra con los registros documentales que se apuntan.

Sobre la demografía de la zona contamos con el pionero trabajo de M. ${ }^{a}$ Inés Carzolio y L. Kofman ${ }^{30}$. Para fechas posteriores R. Lanza realiza un análisis empírico de las crisis de subsistencia lebaniegas y establece una tipología de las mismas ${ }^{31}$.

La historia de la sociedad se ha realizado desde la aproximación a los grupos sociales por parte de Carzolio en diferentes aportaciones ${ }^{32}$. Un silencio casi absoluto envuelve al señorío en Liébana. Un aspecto importante a investigar es la implantación del régimen señorial si tenemos en cuenta que desde el siglo XIV hasta la Desamortización, Liébana fue un territorio profundamente señorializado, diferenciándose en esto del resto de las jurisdicciones que, a partir del s. XVIII comienzan a conformar lo que hoy conocemos por Comunidad Autónoma. Los monasterios y la nobleza, la casa de la Vega primero, y luego sus descendientes el marquesado de Santillana-Ducado del Infantado constituyeron sobre todo el territorio lebaniense un señorío jurisdiccional. Sobre este aspecto es ilustrativo el breve artículo de Sánchez Gómez ${ }^{33}$ referido al siglo XVIII.

Si un silencio casi absoluto rodea al régimen señorial habrá que esperar al siglo XVII para conocer la organización administrativa de Liébana, a excepción de un breve artículo sobre la merindad de Liébana-Pernía, a cargo de Baró Pazos ${ }^{34} \mathrm{o}$ el de Serna Vallejo sobre la época medieval y moderna. Definir los elementos definitorios de los grupos que configuraron la élite de la sociedad política lebaniega,

${ }^{29}$ MONTENEGRO VALENTíN, J.: Santa María de Piasca: estudio de un territorio a través de un centro monástico (857-1252) Valladolid, Universidad de Valladolid, Secretariado de Publicaciones, 1993.

${ }^{30}$ CARZOLIO, M. ${ }^{\text {a }}$ I. y KOFMAN, L.: «Acerca de la demografía astur leonesa y castellana en la Alta Edad media» Cuadernos de Historia de España, 47-48, (1968), pp. 136-170.

31 LANZA GARCÍA, R.: Población y familia campesina en el Antiguo Régimen: Liébana siglos XVIXIX, Santander, 1988.

${ }^{32}$ CARZOLIO, M. - I.: «Identidad política de la vecindad a través de las ordenanzas modernas de Liébana una lenta transición» en Fundación, 5, (2001-2002) pp. 261-288; «Orden, confrontación y estrategias de resistencia del común en la Cantabria de los siglos XVI a XVIII. en Protohistoria, v. 6, (2002), pp. 79-103 y «Vecinos, comunidades de aldea y súbditos del reino. Identidad política en la periferia castellana. Siglos XVI y XVII» en Anales de Historia antigua y Medieval y Moderna, 35- 36. (2003) pp. 269-292.

${ }^{33}$ SÁNCHEZ GÓMEZ, M. A.: «El régimen señorial en Liébana. Un análisis preliminar» en SÁNCHEZ GÓMEZ, M. A. y ESTRADA, M, ed. La Liébana: una aproximación histórica, Torrelavega, 1996, pp. 129-142.

34 BARÓ PAZOS, J.:»La organización administrativa de Liébana en época moderna: Las Juntas de Provincia» en SÁNCHEZ GÓMEZ, M. A. y ESTRADA, M, ed. La Liébana: una aproximación histórica, Torrelavega, 1996, pp. 93-128. 
así como sus luchas políticas por el poder y el sufragio ha estado a cargo de M. Estrada en su tesis desarrollada en 1995 y en otros estudios posteriores ${ }^{35}$.

Hasta aquí las líneas más significativas por las que ha discurrido la historia de Liébana, aunque dejamos aparte otras como la artística, de gran significado desde el siglo XIX y cuyos afanes se han dirigido a los monasterios de Santo Toribio, Santa María de Piasca o Lebeña, a las distintas etapas estilísticas, o al arte religioso en K. Mazarrasa.

Junto a ellas, breves trabajos de derecho, etnografía, biología, flora o geografía. Desde esta última perspectiva destaca la investigación sobre el medio rural y la ordenación del territorio llevada a cabo en dos volúmenes por la Escuela Técnica Superior de Ingenieros de Montes en 1978, Estudios de Planificación Física. El valle de Liébana, o la monografía del Conde de Saint-Saud Por los Picos de Europa. Desde 1881 a 1924 acompañada de mapas e itinerarios realizados por el Coronel León Maury.

Llegamos así a un tema, los caminos, que protagonizan desde los últimos años un devenir que se desarrolla más entre lo turístico-económico que en lo histórico al calor de las diferentes conmemoraciones del Jubileo de Santo Toribio desde hace aproximadamente una década. Así, aparecen el camino de Santo Toribio, la ruta vadiniense, el camino de Santiago por Liébana y la ruta de Pelayo por el momento. Unos itinerarios en los que se mezclan informaciones de distinta índole, en la que todo vale, con objeto de demostrar la existencia de una ruta sin llevar a cabo unos estudios y una metodología que apoyen con más rigor el discurrir de la vía ni tener en cuenta el desarrollo histórico o la articulación preexistente de los territorios por los que se circula.

Desde que en 1572 Ambrosio de Morales diera cuenta de su visita a los monasterios de Santo Toribio y de Piasca y a las iglesias de Lebeña y Naranco y la existencia de reliquias, del lignum crucis y del cuerpo de Santo Toribio, así como «la veneración con que son visitadas de muchas partes», debe transcurrir largo tiempo para conocer detalles sobre el tránsito de viajeros por los caminos lebaniegos, aparte de las menciones puntuales que sobre caminos aparecen en las fuentes documentales. Conocemos detalles sobre rutas lebaniegas procedentes de aquellos que viajaron por nuestro territorio y dejaron escritas sus impresiones. En su caminar, el viajero rara vez desaprovechaba las ocasiones de distracción, conocimiento, diversión o devoción que surgían en torno a su camino, dentro de un entorno enormemente amplio. Descripciones como las aportadas por Hans Gadow, M. Ross y Stonehewer Cooper, o R. Ford se refieren principalmente a la es-

35 ESTRADA, M.: Teoría y práctica del sufragio en España (1834-1874): su aplicación en el caso de Liébana (Tesis doctoral, s. p), U. de Cantabria. 1995, y « ¿Cambio o continuidad?: Ios grupos políticos en La Liébana del siglo XIX» en SÁNCHEZ GÓMEZ, M. A. y ESTRADA, M. (ed.) La Liébana: una aproximación histórica, Torrelavega, 1996, pp. 143-162 y La lucha por el poder: derecho de sufragio y fraude electoral: Liébana 1834-1868, Santander, Parlamento de Cantabria, 1999. 
pectacularidad de los Picos de Europa y al desfiladero de la Hermida, que algunos comparan con Sierra Nevada (California) e incluso con la cordillera del Himalaya ${ }^{36}$. Será Hans Gadow en su libro In northern Spain (1897) quien nos deje entrever un itinerario: desde Unquera/Molleda, Panes, La Hermida, Urdón, Tresviso y Potes, que coincide en grandes rasgos con los de otros viajeros.

Si nos atenemos al trazado del actual camino de Santo Toribio como parte del camino de Santiago por la costa es difícil de imaginar, véase al respecto el trabajo de Álvarez Llopis y Morera Álvarez ${ }^{37}$. Difícil de entender si analizamos el desarrollo del culto o la hagionimia referente a Santo Toribio en Cantabria, una cuestión que debía acometerse junto a otros temas como la arqueología, la articulación del espacio, la influencia del camino de Santiago en la arquitectura y en la creación de villas, solamente presente en el taqueado de Santa María Piasca, fruto quizá de su relación con el monasterio de Sahagún; de las fuentes, con una búsqueda de la petición de jubileo en los Archivos Vaticanos, son cuestiones que pueden plantearse de inicio. Podría hablarse de «caminos» hacia Santo Toribio no del «camino" del que hasta el momento no se ha documentado ninguna mención expresa, aunque si se conozca la asistencia de peregrinos a visitar el monasterio. Las vías más lógicas para llegar a Santo Toribio serían dos: una, las procedentes del camino francés por el sur y el oeste, y otra, las que conectan el territorio lebaniego con los puertos asturianos de Llanes y Avilés, o con Oviedo. Si el actual «camino de Santo Toribio" no se documenta como tal, tanto en los registros documentales o en los itinerarios de Villuga, Meneses, Mercadal, Farinelli u otros, menos aún se registran el calificativo de "crucenos" aplicado a los peregrinos. Una palabra inexistente en el Diccionario de la Real Academia de la Lengua.

No podemos negar la afluencia de peregrinos ni la existencia del camino de San Vicente a Lamasón, el antiguo camino del Potro, usado principalmente por los mercaderes de San Vicente de la Barquera para evitar el pago del portazgo de Cires o los asaltos por parte de las gentes del señorío de Velasco. Objeto de estudio por las autoras más arriba citadas, en el que se intenta reconstruir, a pesar de los grandes vacíos cronológicos y documentales existentes, no solo la posible existencia del "Camino de la Costa», sino también los diferentes ejes vertebradores desde los puertos del litoral cantábrico hacia el Camino Francés ${ }^{38}$. Por su parte, Ansola Fernández y Sierra Alvarez en su estudio sobre este camino, realizado para fechas más tardías, coinciden con Álvarez Llopis en la necesidad de profundizar documental y arqueológicamente en su estudio. El mismo camino ha sido analizado y cartografiado dentro del Proyecto Nansa de la Fundación Marce-

${ }^{36}$ M. ROSS y STONEHEWER COOPER: The highlands of Cantabria; or three days from England, cap. XI, XII a XIX, 1884.

37 ÁlVAREZ LLOPIS, E. y MORERA ÁlVAREZ, M.: Camino Norte I. Cantabria. La Coruña, Hércules de Ediciones, 2009, pp. 274-285.

38 ÁlVAREZ LLOPIS, E. y MORERA ÁLVAREZ, M.: op. cit. 
lino Botín. Queda claro que existe el camino y su utilización por diferentes motivos, pero somos escépticos en su identificación como «camino de Santo Toribio».

Desde una perspectiva general es la aproximación al tema de los caminos de Álvarez Llopis y Blanco Campos ${ }^{39}$.

Por lo que se refiere a la ruta vadiniense esta ha sido objeto más de acercamientos locales o virtuales que de un verdadero estudio histórico. De la «ruta de Pelayo» sólo conocemos el trazado realizado por Sánchez Albornoz y la hipótesis de su trazado sugerida por algunos conocedores locales.

\section{VALORACIÓN FINAL}

A lo largo de estas páginas hemos agrupado los trabajos realizados según las líneas dominantes de las distintas propuestas historiográficas por las que ha transcurrido la historia del territorio lebaniense. Valorar ahora estas exige, en cierto modo, resaltar el evidente desequilibrio informativo que existe, tampoco es complicado deducir en algunos de ellos una cierta ausencia de planteamientos teóricometodológicos.

Es notable en la historiografía lebaniega la escasez de síntesis, representada únicamente por las de Álvarez Llopis y Estrada Gómez, tan alejadas en el tiempo y en la temática que poco pueden servir para conocer la evolución del territorio. Sigue persistiendo la tradición positivista de la publicación de fuentes, quizás debida a la abundante producción monástica, ampliada con las fuentes lingüísticas. Existe en cambio una ausencia total sobre temas relativos al comercio, el señorío, los estudios sobre la creación de las aldeas, con objeto de conocer la ordenación del espacio por parte de la sociedad; tampoco existe una aproximación al ejercicio del poder, los conflictos sociales como respuesta al señorío,... Son tantas las carencias como abundantes los estudios relativos a la obra de Beato de Liébana.

Cronológicamente, la hegemonía corresponde a época medieval, los trabajos sobre este período superan en número a los relativos a las restantes etapas históricas.

Notable también es la persistencia de una historia local apoyada en la leyenda y el mito, que continua con la repetición de tópicos presente en los viejos mitos del vasco-cantabrismo.

En definitiva, podemos pensar que se olvida la historia de un territorio, diferenciado, el lebaniense, o de una comarca que ofrecía mayor homogeneidad, la «Provincia de Liébana», en beneficio de una promoción turística comarcal y regional,

39 ÁLVAREZ LLOPIS, E. y BLANCO CAMPOS, E.: «Las vías de comunicación en Cantabria en la Edad Media, I Encuentro de Historia de Cantabria». Santander, 1999, pp. 491-521. 
que se apoya en el turismo religioso o de peregrinación vinculado a un proceso de elaboración de símbolos asociados a un lugar de culto: Santo Toribio, y a un espacio turístico: los Picos de Europa, que se sustenta en una amplia campaña publicitaria desde la celebración del Jubileo de 2006 que busca rentabilidad social e ideológica, además de económica.

\section{APÉNDICE BIBILIOGRÁFICO. EDAD MEDIA ${ }^{40}$}

ÁLVAREZ LLOPIS, E.: Liébana medieval, siglos IX a XII. Instalación humana y actividades económicas (Tesis doctoral s. p), Universidad de Cantabria, 1994.

ÁLVAREZ LLOPIS, E.: «Introducción a la Liébana medieval» en La Liébana una aproximación histórica, Estrada, M y Sánchez Gómez, M. A. (eds.) Torrelavega, pp. 77- 93, 1996.

ÁLVAREZ LLOPIS, E.: «Molinos hidráulicos en Cantabria, siglos X al XIII» en El fuero de Santander y su época. Santander, Ed. Estudio, 1989, pp. 411-423.

ÁLVAREZ LLOPIS, E.: «Espacio y tiempo de trabajo femenino en la Edad Media (ss. XIII-XVI)» en Congreso Internacional El trabajo de las mujeres. Pasado y presente, RAMOS, M. D. y VERA, M. T. (eds) T. II, Universidad de Málaga, 1992, pp. 145-154.

ÁLVAREZ LLOPIS, E.: «Técnica molinera entre el Cantábrico y el Arlanzón», Revista de folklore, 101, (1989), pp. 147-160.

ÁLVAREZ LLOPIS, E.: «Hagionimia y Hagiotoponimia en Liébana: siglos IX-XIII» en // Encuentro de Historia de Cantabria. Solórzano, J. A. y González Morales, M. (coord): vol. I, (2005), pp. 259-276.

ÁLVAREZ LLOPIS, E.: «La toponimia de Liébana: nuevas propuestas de organización social del espacio" en La onomástica en Navarra y su relación con la de España. Actas de las I Jornadas de Onomástica (Pamplona 2003), J. L. SÁDABA (coord), Pamplona, Universidad Pública de Navarra, 2005, pp. 317-337.

ÁLVAREZ LLOPIS, E.: El molino, del Cantábrico al Arlanzón entre los siglos X al XIII: instrumento de trabajo y medio de presión señorial, (Memoria de licenciatura), Universidad de Cantabria, 1986.

ÁLVAREZ LLOPIS, E.: «Liébana y el Jubileo de Santo Toribio» Pedrueca, 2, (2005), pp. 44-47.

ÁLVAREZ LLOPIS, E.: «Aldeas y solares en Liébana: Argüébanes, Turieno y Potes» en Del Cantábrico al Duero: trece estudios sobre organización social del espacio en los siglos VIII a XIII. García de Cortázar, J. A. (coord.), Santander, 1999, pp. 189-228.

ÁLVAREZ LLOPIS, E.: «Introducción Histórica. El País Vasco y Cantabria» en La Gran obra de los Caminos de Santiago, Camino Norte I, País Vasco, coord. Vázquez Portomeñe, S., T. XII, La Coruña, Hércules de Ediciones, 2009, pp. 18-39.

ÁLVAREZ LLOPIS, E. y MORERA ÁLVAREZ, M.: «La ruta del Nansa. De Puente Nansa hacia Lamasón y Liébana» en La Gran obra de los Caminos de Santiago, Camino Norte II. Cantabria, coord. Vázquez Portomeñe, S. T. XIV, La Coruña, Hércules de Ediciones, 2009, pp. 274-285.

ÁLVAREZ LLOPIS. E.: «Los caminos norte-sur» en La Gran obra de los Caminos de Santiago, Camino Norte III. Asturias y Galicia, coord. S. Vázquez Portomeñe, T. XV, La Coruña, Hércules de Ediciones, 2013.

ÁLVAREZ LLOPIS, E., BLANCO CAMPOS, E.: «Las vías de comunicación en Cantabria en la Edad Media» en I Encuentro de Historia de Cantabria, Santander, 1999, pp. 491-521.

40 Por razones de espacio hemos limitado el apéndice a las obras que pueden incluirse dentro del espacio cronológico de la Edad Media. 
ÁLVAREZ LLOPIS, E., BLANCO CAMPOS, E. y GARCÍA DE CORTÁZAR, J. A.: Colección diplomática de Santo Toribio de Liébana, 1300-1515. Santander, Fundación «Marcelino Botín», 1994.

ÁLVAREZ LLOPIS, E. y PEÑA BOCOS, E.: «La maison paysanne dans le Nord-oueste de la Péninsule Ibérique au Bas Moyen Age: une cellule de base de l'organisation sociale de l'espace» en Maisons paysanne en Europe occidentale. XVe- XX/e siècles. Jean-René Trochet (dir). Presse de l'Université París- Sorbonne, 2008, pp. 17-30.

ÁLVAREZ LLOPIS, E. y PEÑA BOCOS, E.: « Los territorios de la Cantabria medieval» en Historia de Cantabria. Historia Medieval. t. I. Santander, Editorial Cantabria, 2007, pp. 169-176.

ANSOLA FERNÁNDEZ, A., SIERRA ÁLVAREZ, J.: «El camino real de la Montaña: de Liébana a la costa por el valle de Lamasón (Cantabria)", Ería, revista cuatrimestral de Geografía, 71, (2006), pp. 319-337.

ARTEAGA FALGUERA, C.: La casa del Infantado, cabeza de los Mendoza, Madrid, [s.n.] 1940.

BARBERO, A. y VIGIL M.: La formación del feudalismo en la península ibérica, Barcelona, Crítica, 1978.

BARBERO, A. y VIGIL M.: Sobre los orígenes sociales de la Reconquista, Barcelona, Ariel, 1974

BARBERO, A. y VIGIL M.: «Sobre los orígenes sociales de la reconquista: cántabros y vascones desde fines del imperio romano hasta la invasión musulmana» Boletín de la Real Academia de la Historia, CLVI, 2, (1965), p. 271-339.

BARÓ PAZOS, J. (ed): La historia de Liébana a través de sus documentos, Santander, 2000.

BARÓ PAZOS, J.: «El derecho y la administración de justicia en Liébana en época medieval y moderna» en Baró Pazos, J. (ed): La historia de Liébana a través de sus documentos, Santander, 2000.

BERMEJO CASTRILLO, M. A.: «La Cantabria medieval: del aislamiento a la apertura» Alondra,4, (1990), pp. 20-26.

BLASCO MARTínEZ, R.: Los cartularios de Cantabria: Santo Toribio. Santa María del Puerto, Santillana y Piasca. Estudio codicológico, paleográfico y diplomático, Santander, Estudio, 1989.

BOHÍGAS ROLDÁN, R.: «Levantamiento planimétrico y prospección electromagnética del claustro y entorno de Santa María de Piasca. Cabezón de Liébana», en Actuaciones arqueológicas en Cantabria 1984-1999 (coord.). R. Ontañón, Santander, pp. 254-353, 2000.

BOHÍGAS ROLDÁN, R.: Los restos arqueológicos altomedievales en Cantabria (Tesis doctoral s. p), Universidad de Valladolid, 1982.

BOTELLA POMBO, E.: La Serna (800-1250): ocupación, organización y explotación del espacio, Santander, Tantín, 1988.

CABALLERO. C. et alii: «Libro apeo del Monasterio de Santo Toribio de Liébana (año 1499)» en Anales de Historia Antigua, Medieval y Moderna, 43 (2012), pp. 219-322.

CABALLERO. C. et alii: «Libro apeo del Monasterio de Santo Toribio de Liébana (año 1499)" Segunda Parte en Anales de Historia Antigua, Medieval y Moderna, 45 (2012), pp. 219-322.

CALDERÓN ORTEGA, J. M.: «Cuantificación de la renta señorial en la Liébana. La renta de la tierra en el s. XVI» Altamira, I, (1978), pp. 91-97.

CANAL SÁNCHEZ PAGÍN, J. M. ‥ «Toponimia euskera y prerromana en los valles de Liébana» Estudios humanísticos, Filología, 20, (1998), pp. 11-26.

CARRETERO BAJO, A. E.: «El régimen señorial en Cantabria: fuentes documentales, I. Introducción y estadística» Publicaciones del Instituto de Etnografía y Folklore «Hoyos Sainz, XIII, (1987-1989), pp. 267-287.

CARZOLIO, M. ${ }^{\text {a }}$ I.: «Formas de gestión del patrimonio monástico en Santo Toribio de Liébana, siglo XV y XVI» Cuadernos de Historia de España, 74, (1997), pp. 29-66.

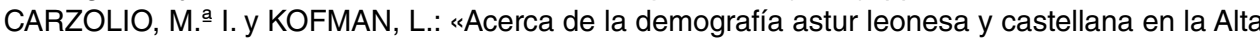
Edad Media», Cuadernos de Historia de España, 47-48, (1968), pp. 136-170. 
CASADO TEJERO, L.: La cristalización de la red parroquial en el espacio de la actual diócesis de Santander. (Trabajo de investigación de tercer ciclo), Universidad de Cantabria, 1986.

CASADO TEJERO, L.: «La organización parroquial en el espacio de la actual Diócesis de Santander (790-1220)» en El fuero de Santander y su época, Santander, Estudio, 1989, pp. 65-73.

CUESTA BEDOYA, J. et alii: «Localización de los antiguos monasterios de Liébana» Clavis, 1, (1996), pp. 7-98.

DÍEZ CASTILLO, A.: Inventario arqueológico de la comarca de Liébana: evolución, historia y poblamiento (Tesis doctoral s. p), Universidad de Cantabria, 1991.

DÍEZ HERRERA, C.: «Algunos aspectos de la vida cotidiana de la Liébana en la Edad Media» en La vida cotidiana en una aldea Lebaniega. Siglos XVIII-XIX, Santander, Universidad de Cantabria - Aula de Etnografía, 1992, pp. 25-36.

DÍEZ HERRERA, C.: La formación de la sociedad feudal en Cantabria. Santander, Universidad de Cantabria-Asamblea Regional de Cantabria, 1990.

DÍEZ HERRERA, C.: «La Liébana altomedieval: del espacio «escrito» al espacio interpretado» en Liébana y letras, (coord) V. Carracedo, Santander, 2008, pp. 11-24.

DÍEZ HERRERA, C.: «Un ejemplo de enfrentamiento entre dos instituciones de poder local: Santo Toribio y la villa de Potes en la Baja Edad Medía» en Castilla y el mundo feudal. Homenaje al profesor Julio Valdeón Val Valdivielso, M. a I, y Martínez Sopena, P. (coord.). Universidad de Valladolid, 2009, vol. 3, pp. 111-124.

DUART GAITERO, C.: «Vasallos y rentas de Diego Hurtado de Mendoza, III Duque del Infantado en la Merindad de Liébana en 1501 » Altamira, 40, (1976-1977), pp. 231-246.

ESCAGEDO SALMÓN, M.: Vida monástica de la provincia de Santander, T. I. Liébana y Santillana, Torrelavega, 1918.

ESCALONA, R.: Historia del real monasterio de Sahagún sacada de la que dexo escrita el $P$. Josph Pérez corregida y aumentada. 1782.

FERNÁNDEZ CATÓN, J. M.․: Monasterio de Sahagún (857-1300), León, Centro de Estudios e Investigación San Isidoro, 1999.

FERNÁNDEZ FLÓREZ, J. A.: «El Becerro de las Presentaciones: códice 13 del Archivo de la Catedral de León. Un parroquial leonés de los ss. XIII-XV» en León y su historia, León, 1984, pp. 477-484.

FERNÁNDEZ FLÓREZ, J. A.: Colección diplomática del monasterio de Sahagún (857-1300), IV (1110-1199). León, Centro de Estudios e Investigación San Isidoro, 1991.

FERNÁNDEZ FLÓREZ, J. A.: Colección diplomática del monasterio de Sahagún (857-1300), V (1200-1300). León, Centro de Estudios e Investigación San Isidoro, 1993.

FITA, F.: «El monasterio dúplice de Piasca y la regla de San Fructuoso de Braga en el siglo X» Boletín de la Real Academia de la Historia, XXXIV, (1899), pp. 448-462.

FITA, F.: «San Miguel de Escalada y Santa María de Piasca: datos inéditos» Boletín de la Real Academia de la Historia, XXXIV, (1899), pp. 311-343.

FITA, F.: «Santa María de Piasca y el primer concilio de Oviedo» Boletín de la Real Academia de la Historia, XXXIV, (1899), pp. 311-343 y 549-555.

FRAILE LÓPEZ, M. A.: Historia social y económica de Cantabria (hasta el siglo X), Reinosa, Copisán, 1990.

GARCÍA DE CORTÁZAR, J. A., DÍEZ HERRERA, C. y PEÑA BOCOS, E.: «Antroponimia y sociedad del Cantábrico al Ebro en los siglos IX a XIII» en Antroponimia y sociedad en el norte de la península ibérica, Universidad de Valladolid - Universidad de Santiago de Compostela, 1994.

GARCÍA DE CORTÁZAR, J. A. y DÍEZ HERRERA, C.: La formación de la sociedad hispano-cristiana del Cantábrico al Ebro en los siglos VIII al XI: planteamiento de una hipótesis y análisis del caso de Liébana, Asturias de Santillana y Trasmiera, Santander [s.n.], 1982. 
GARCÍA DE CORTÁZAR, J. A. y DÍEZ HERRERA, C.: «La formación de los dominios monásticos en Cantabria años 800-1200: una primera pista para el estudio de la evolución histórica de una sociedad regional» en I Semana de Historia del Monacato Cántabro Astur-leonés, Oviedo, 1982, pp. 57-80.

GARCÍA GUINEA, M. A. (dir.): Historia de Cantabria: prehistoria, edades antigua y media, Santander, Librería Estudio, 1985.

GARCÍA GUINEA, M. A.: «El monasterio de Santo Toribio de Liébana» Anales de Estudios Medievales, 2, (1965).

GARCÍA GUINEA, M. A.: Inventario del Patrimonio Artístico y Monumental de Cantabria: I. Liébana, M. A. García Guinea y M. A. Puente Sañudo (coord.). Santander, Diputación Regional de Cantabria, 1989.

GARCÍA LOMAS, G. A.: «La hidronimia arcaica en la Cantabria montañesa» Altamira, 1-3, (1965), pp. 293-319.

GARCÍA-LOMAS, G. A.: «Notas para el estudio de la toponimia montañesa» Altamira, 1, (1945), pp. 63-78.

GARCÍA SAHAGÚN, J.: La organización del espacio agrario en Liébana durante la Edad Media, Santander, [s.n.] 1986.

GAUTIER-DALCHÉ, J.: «Le domaine du monastère de Santo Toribio de Liébana: formation, structure et modes d'explotation» Anuario de Estudios Medievales, 2, (1965), pp. 65-118.

GONZÁLEZ COTERA, J. M.a: Pasajeros a Indias de Liébana y sus valles circundantes 1503-170, según la documentación de Archivo General de Indias. ed. digital 2005.

GONZÁLEZ COTERA, J. M.a.: Apeo del Monasterio de Santa María la Real de Piasca. Año 1532. ed. digital. 2012.

GONZÁLEZ ECHEGARAY, J.: «Beato de Liébana y los terrores del año 800» en Milenarismos y Milenaristas en la Europa Medieval, IX Semana de Estudios Medievales, coord. J. E. de la Iglesia Duarte, Nájera 1998, pp. 187-100.

GUTIÉRREZ CUENCA, E. y MANTECÓN CALLEJO, L.: «Dos nueva necrópolis medievales en la comarca de Liébana (Cantabria), Nivel cero, revista del grupo arqueológico Attica, 10, (2002), pp. 129-137.

GUTIÉRREZ DE SARA, J.: «Monasterio de Santo Toribio de Liébana» Semanario Pintoresco Español, (1857), pp. 73-75.

HERRERO DE LA FUENTE, M.: Colección Diplomática del Monasterio de Sahagún (857-1230), I (1074-1109). León, Centro de Estudios e Investigación San Isidoro, 1988.

Historia de Liébana a través de sus documentos (exposición), Gobierno de Cantabria, Dirección General de Cultura, 2000 (coord.). BARÓ PAZOS, J.

HUARTE, A.: Los contratos de Doña Leonor de la Vega, Salamanca [s.n.], 1923.

INGELMO CASADO, R.: «Las sernas en la comarca de Liébana (Cantabria): Génesis, evolución y situación actual de un espacio tradicional». Documentos de trabajo 2011-3, CEDDAR: DT (2011-3) (Centro de Estudios sobre la Despoblación y Desarrollo de Areas Rurales), (2009) n. ${ }^{\circ} 32011$, pp. 1-47.

ISLA FREZ, A.: «El adopcionismo y las evoluciones religiosas y políticas en el Reino Astur» Hispania, vol. 58, 200, (1998), pp. 971-993.

JUSUÉ, E.: Copia de cuatro cartas inéditas del Cartulario de Santo Toribio de Liébana, Santander [s.n.], 1904.

JUSUÉ, E.: «Documentos inéditos del Cartulario de Santo Toribio de Liébana (años 796-828) durante el reinado de Alfonso II» Boletín de la Real Academia de la Historia, 47, (1905), pp. 69-76.

JUSUÉ, E.: «Documentos inéditos del Cartulario de Santo Toribio de Liébana (año 831) durante los reinados de Alfonso II, Ramiro I y Fruela» Boletín de la Real Academia de la Historia, 48, (1906), pp. 131-139. 
JUSUÉ, E.: «El libro Cartulario del monasterio de Santo Toribio de Liébana que se conserva en el Archivo Histórico Nacional: (sección códices y Cartularios, 990B)» Boletín de la Real Academia de la Historia, 45, (1904), pp. 409-421.

JUSUÉ, E.: Monasterio de Santo Toribio de Liébana: precedido de una carta prólogo del P. F. José de las Cuevas. 2.ำ ed. corregida y aumentada con fotograbados, 1921.

JUSUÉ, E.: Provincia de Santander: Monasterio de Santo Toribio de Liébana, Valladolid, Impr. Libr. de Andrés Martín Sánchez, 1921 Ed. anterior: Madrid, 1892.

LAVÍN DEL NOVAL, V.: «Sobre el monasterio de Santo Toribio de Liébana» Boletín de la Real Academia de Bellas. Artes de San Fernando, 1, (1953), pp. 81-82.

LÓPEZ LINAJE, J.: Antropología de la ferocidad cotidiana; supervivencia y trabajo en una comunidad cántabra. Madrid, Ministerio de Agricultura, Pesca y Alimentación, 1978.

LÓPEZ SERRANO, M.: Libro de la montería del Rey de Castilla Alfonso XI: estudio preliminar. Madrid, Patrimonio Nacional, 1974.

LORING GARCÍA, I.: Cantabria en la Alta Edad Media: organización eclesiástica y relaciones sociales. Madrid, Universidad Complutense, 1987.

LORING GARCÍA, I.: «Nobleza e iglesias propias en la Cantabria alto medieval» Studia Storica. Historia Medieval, 5, (1987), pp. 89-121.

MADRAZO, P. de: «La iglesia de Santa María de Lebeña» Boletín de la Real Academia de la Historia, XXII, (1893), pp. 289-293.

MARCOS MARTÍNEZ, J. y MANTECÓN CALLEJO, L.: «El castillo de Monte Subiedes (Camaleño, Liébana, Cantabria); control del territorio lebaniego en la Alta Edad Media» Territorio, sociedad y poder: revista de estudios medievales, 4, (2009), pp. 95-129.

MARTíN MíNGUEZ, B.: De la Cantabria, Santillana, San Martín y Santo Toribio y Santa María de Lebeña (Liébana), Santa María del Puerto (Santoña). Madrid, Tip. de la Revista de Archivos, Bibliotecas y Museos, 1914.

MARTÍNEZ DÍEZ, G.: Libro Becerro de las Behetrías. Estudio y texto crítico. 3 vols. León, 1980.

MARTÍNEZ DE VELASCO, L.: «Santo Toribio de Liébana» Semanario Pintoresco Español, (1849), pp. 177-179.

MARTÍNEZ DE VELASCO, L.: «Sobre el monasterio de Liébana» Boletín de la Real Academia de Bellas Artes de San Fernando, (1853-1854) pp. 81.

MARTíNEZ JÉREZ, L.: «El monasterio de Valcavado y San Beato de Liébana» Publicaciones de la Institución «Tello Téllez de Meneses», 32, (1971), pp. 247-265.

MARTÍNEZ MARTÍNEZ, S. y FUENTE ROYANO, M. T. a de la: De la viña a la bodega: doce siglos de viñedo en Liébana. Liébana, Sociedad de Amigos del País de Liébana, 2002.

MARTÍNEZ MARTÍNEZ, S. y FUENTE ROYANO, M. T. ${ }^{\text {a }}$ de la: Liébana en mil palabras. Santander, Consejería de Cultura, Educación y Deporte, 2006.

MARTÍNEZ MARTÍNEZ, S. y FUENTE ROYANO, M. T. a de la: El marqués de Santillana, señor de Liébana, textos, Frente de Afirmación Hispanista, México, 2011.

MARTÍNEZ SOPENA, P.: «Parentesco y poder en León durante el siglo XI. La «casata» de Alfonso Díaz» Studia Histórica. Historia Medieval, 5 (1987), pp. 33-87.

MAZA SOLANO, T.: «Santa María de Piasca: (un manuscrito de 1519)» Boletín de la Biblioteca Menéndez Pelayo, I, (1919), pp. 128-141.

MAZARRASA, K.: Liébana: arquitectura y arte religioso, siglos XV-XIX, Santander, 2009.

MÍNGUEZ FERNÁNDEZ, J. M.ạ: Colección diplomática del monasterio de Sahagún (siglos IX-X). León, Centro de Estudios e Investigación San Isidoro, 1977.

MíNGUEZ, J. M. a , FERNÁNDEZ FLÓREZ, J. A. y HERRERO DE LA FUENTE, M.: Colección diplomática del monasterio de Sahagún, 4, León, Centro de Estudios e Investigación San Isidoro, 1991.

MOLENAT, J. P.: «Chemins et ponts du Nord de Castille au temps des Rois Catholiques» Melanges de la Casa de Velázquez, VII, (1971), pp. 115-162. 
MONTENEGRO VALENTíN, J.: Colección Diplomática de Santa María de Piasca (857-1252, Santander, Diputación Regional, 1991.

MONTENEGRO VALENTÍN, J.: Liébana y Santa María de Piasca (857-1252), (Tesis doctoral, s. p), Universidad de Valladolid, 1986.

MONTENEGRO VALENTÍN, J.: «Organización territorial en Liébana durante la Edad Media: valles y alfoces» en El fuero de Santander y su época. Santander, Ed. Estudio, 1989, pp. 77-94.

MONTENEGRO VALENTÍN, J.: Santa María de Piasca: estudio de un territorio a través de un centro monástico (857-1252). Valladolid, Universidad de Valladolid, Secretariado de Publicaciones, 1993.

MONTENEGRO VALENTÍN, J.: «Antroponimia lebaniega en los siglos IX al XII» en Antroponimia y sociedad: sistemas de identificación hispano-cristianos en los siglos IX al XIII. Martínez Sopena, P. (coord), 1995, pp. 181-204.

MONTENEGRO VALENTÍN, J. y CASTILLO ÁLVAREZ, A. del: «Don Pelayo y los orígenes de la Reconquista» Hospania: Revista española de historia, v. 52, 180, (1992), pp. 5-32.

MONTENEGRO VALENTÍN, J. y CASTILLO ÁLVAREZ, A. del: « De nuevo sobre don Pelayo y los orígenes de la Reconquista» Espacio, tiempo y forma, Serie II, Historia Antigua, 8, (1995), pp. 507-520.

MUÑOZ JIMÉNEZ, J. M.: «Caminos y fortificaciones en la Cantabria medieval» en El Fuero de Santander y su época. Santander, 1989, pp. 443-453.

ORTIZ REAL, J.: «Aproximación a la historia de Liébana» en Liébana: la tierra como era. Torrelavega, 1985, pp. 89-101.

PEÑA BOCOS, E.: «La organización político-administrativa y diocesana de Cantabria antes de la concesión del fuero de Santander (siglos VIII-XII)» en El fuero de Santander y su época. Santander, Estudio, 1989, pp. 97-111.

PÉREZ BUSTAMANTE, R.: «El régimen municipal de la villa de Potes a fines de la Edad Media» Altamira, 42, (1979-1980), pp. 187-214.

PÉREZ BUSTAMANTE, R.: «El proceso de consolidación de un dominio solariego en la Castilla bajomedieval: El señorío de la Vega (1367-1432), Altamira, 40, (1976-1977), pp. 95-143.

PÉREZ BUSTAMANTE, R.: «Inventario de los bienes raíces de Leonor de la Vega» Revista de Archivos, Bibliotecas y Museos, 1, (1978), pp. 73-104.

PÉREZ BUSTAMANTE, R.: «Liébana y la Casa del Infantado: cuestiones de régimen señorial, s. XV-XVI» en Homenaje a J.A. Maravall, Madrid, 1984.

PÉREZ BUSTAMANTE, R.: Sociedad, economía, fiscalidad y gobierno en las Asturias de SantiIlana (S. XIII-XV). Santander, Librería Estudio, 1979.

PÉREZ BUSTAMANTE, R.: «Un padrón municipal de la villa de Potes, 1415: (notas para su estudio)» Publicaciones del Instituto de Etnografía y Folklore «Hoyos Sainz», 11, (1981-1983), pp. 273-292.

PÉREZ BUSTAMANTE, R.: «Venta de un vasallo en el siglo XV» Altamira, 38, I, (1974), p. 245-247.

PÉREZ DE URBEL, Fr. J.: «Documentos de Santa María de Piasca» en Historia del Condado de Castilla, Apéndice, III, Madrid, Consejo Superior de Investigaciones Científicas; Escuela de Estudios Medievales, 1945, pp. 1369-1382.

PONTIERI, M.: «Una familia de propietarios rurales en la Liébana del siglo X» Cuadernos de Historia de España, 43-44, (1967), pp 119-132.

PORRO, R. N.: «Tres documentos sobre fijosdalgo castellanos" Cuadernos de Historia de España, XXXIII-XXXIV, (1961), pp. 355-366.

RAMíREZ SÁDABA, J. L. «A propósito del Cartulario de Santa María de Piasca: reflexiones sobre el tratamiento informático de los antropónimos» Patronymica romanica, 5. Dictionaire Historique des Noms de Famille Romans, Tübingen, 1991, pp. 21-33. 
RAMíREZ SÁDABA, J. L.: «Antroponimia del cartulario de Santa María de Piasca» en Actas del XIX Congreso Internacional de lingüística e filoloxía románicas, IV, La Coruña, pp. 565-580, 1993.

RAMíREZ SÁDABA, J. L.: Liébana: toponimia e historia. Santillana del Mar, Museo de las Comarcas de Cantabria, Gabinete Didáctico, 1992.

RAMíREZ SÁDABA, J. L. y ROBLES, J. M.: «La antroponimia medieval de Liébana» en Patronymica Romanica. Dictionnaire Historique des Noms de Famille Romans, Tübingen, 1990, pp. 81-92.

RÁMIREZ SÁDABA, J. L., ROBLES, J. M.: «La antroponimia medieval de Liébana» en El Fuero de Santander y su época: actas del congreso commemorativo de su VII centenario, 1997, pp. 447-490.

RODRÍGUEZ VALENCIA, V.: «Santo Toribio Alfonso de Mogrovejo», Archivos Leoneses, 8, (1950), pp. 5-34.

RUBIO GARCÍA, M.: Documentos sobre el marqués de Santillana, Murcia, 1983.

RUESGA HERREROS, L.: «La merindad de Liébana y Pernía, apunte histórico» Altamira, 68, (2005), pp. 93-102.

SAINZ DE ROBLES, F.: Elipando y San Beato de Liébana. Siglo VIII. Madrid, M. Aguilar, 1934.

SAN MIGUEL PÉREZ, E.: Nobleza, territorio y poder político: Cantabria, siglos XIII-XV (Tesis doctoral s. p), Universidad de Cantabria, 1990.

SÁNCHEZ ALBORNOZ, C.: “Contratos de arrendamiento en el reino Astur-leonés» Cuadernos de Historia de España, X, (1948), p. 142-179.

SÁNCHEZ ALBORNOZ, C.: «Serie de documentos inéditos del reino de Assturias» Cuadernos de Historia de España, 1-2 (1944).

SÁNCHEZ BELDA, L.: Cartulario de Santo Toribio de Liébana, Madrid, Patronato Nacional de Archivos Históricos, 1948.

SÁNCHEZ GÓMEZ, M. A.: «La abolición del régimen señorial en Cantabria», en I Encuentro de Historia de Cantabria. Santander, Universidad de Cantabria - Gobierno de Cantabria, 1999, pp. 883-889.

SÁNCHEZ GÓMEZ, M. A.: «El régimen señorial en la Liébana. Un análisis preliminar» en La Liébana: una aproximación histórica, Sánchez Gómez, M. A. y Estrada, M. (eds.), Santander, 1996, pp.129-142.

SÁNCHEZ GÓMEZ, M. A. y ESTRADA, M. (eds). La Liébana: una aproximación histórica, Santander, 1996.

SERNA VALLEJO, M.: «El gobierno y la administración de Liébana en época medieval y moderna» en La historia de Liébana a través de sus documentos, Baró Pazos, J. (ed), Santander, 2000, pp. 16-45.

SOTA, F.: Chronica de los príncipes de Asturias y Cantabria consagrada a la sacra y real magestad del rey nuestro señor Don Carlos II rey de las Españas y Nuevo Mundo. Madrid, 1681.

VAN DEN EYDE CERUTTI, E.: «Plan general de investigación de la arquitectura monástica altomedieval. Prospecciones arqueológicas en los yacimientos de los monasterios altomedievales de Osina, Aguas Cálidas, Cosgaya y Naranco» en Actuaciones arqueológicas en Cantabria, 1984-1989, Ontañón Peredo, R. (coord) 2000, pp. 87-88.

VAN DEN EYDE CERUTTI, E. e ILLARREGUI GÓMEZ, E.: «Un ejemplo de integración de una necrópolis medieval sobre una estructura romana» Coloquio sobre el microespacio-4. Época Romana y Medieval, Teruel, Arqueología Espacial, 10, 1986, pp. 159-171.

VAQUERIZO GIL, M.: « La economía y la hacienda de Liébana» en La historia de Liébana a través de sus documentos, Baró Pazos, J. (ed.), Santander, 2000, pp. 77-118.

VASALLO, R.: Estructura y dinámica del dominio de Santo Toribio de Liébana (siglos XIII-XVI) (Tesis doctoral, s. p.), Universidad de Salamanca, 2003. 
VASALLO, R.: «Estructuras de poder local en señoríos de abadengo (siglos XIV-XVI)», Informe 2006.

VASALLO, R., GRACA, L. da, y CARZOLIO, M. a I.: Documentación del Monasterio de Santo Toribio de Liébana: apeos de 1515 y 1538, Santander, Fundación Marcelino Botín, 2001.

VV. AA.: El Fuero de Santander y su época: actas del Congreso Conmemorativo de su VIII centenario. Santander, Estudio, 1989.

ZARAGOZA PASCUAL, E.: «Abadologio y priorologio de Santa Toribio de Liébana (siglos IX-XIX), Altamira, 67. (2005), pp. 35-64. 